\title{
Relationship among Trust, Justice and Organizational Commitment at Hospitals in Nepal
}

\author{
Binod Ghimire \\ Lecturer, Nepal Commerce Campus
}

\begin{abstract}
The main purpose of this research is to examine the relationships among trust, justice and organizational commitment at hospitals in Nepal. The success of an organization is closely related to its employees' perception of trust, and justice within the organization. This study is based on the effect of perceptions of trust in management and organizational commitment among the nurses working in different hospital at Kathmandu Valley. This study includes the design and distribution of a self-administered questionnaire to 465 nurses belonging to different hospitals working on different basic pay scales.This paper is useful to academicians and organizations to understand the level of relationship that will help them to manage the organization in accordance with its objectives. Improved treatment of organizational and developing mutual trust and understanding between management and workers lead to the organizational commitment.
\end{abstract}

Key words: Trust, Justice, Commitment

\section{Introduction}

Organizational trust and organizational justice are recognized as the factors that promote organizational commitment (Wong, 2003). If the employees rely on the organization, this affect their level of commitment relations to the organization and as well as to the administrators. Trust makes employees not only share common values but also bear more responsibility as being a member of the organization. Employees' trust in management develops as employers and employees view that the investments in the relationship are offset by returns. It is based on the norm of reciprocity (Gouldner, 1960). A research study by Pillai et al. (2001) found out that when distributions of organizational outcomes are considered to be fair, the higher employee levels of trust are likely to develop. This is supported by earlier research by Herriot et al. (1998) who argued that trust manifestation is based on the fulfillment of perceived obligation. In a related argument, Brockner and Siegel (1996) suggested that positive employees' views of processes and procedures are related to higher employees' level of trust in the organization. In addition, Bakhshi, Kumar and Rani (2009) study showed that when employees felt that they were treated fairly by their company, they were likely to hold more trust in management.

\section{Organizational Trust}

Trust is interrelated with the context in which it is constructed. In this context, phenomenon "trust" is defined in an organizational setting, and in terms of a bi- 
party relationship between employees and those to whom these employees directly report to. Mayer, Davis, and Schoorman (1995) argue that trust involves risk, as one or more parties make themselves vulnerable to the actions or non-actions of others. They also distinguish between trust and other concepts such as cooperation, confidence, and predictability pointing out that what is lacking in all three concepts is vulnerability and risk. According to them, risk is apparent in an active willingness to place trust as opposed to the passive intent of showing trust, which would make trust somewhat shallow. There exists certain moral commitment attached to an employment relationship, moving it on a slightly higher level than one based purely on economic grounds. In an employer-employee relationship, there is a responsibility to act in the interest of the employer at all times. On the other hand, there is an equal responsibility to consider the employees' interests. Consequently, trust in the workplace functions on a reciprocal basis and tends to carry with it a positive intention of acting in another's interests, thus distinguishing it from confidence, cooperation, and reliance, all of which are more passive in nature.

\section{Organizational Justice}

Employees react various favorable or unfavorable behavior according to the outcomes of organizational justice which they perceive in the work environment as suggested by Adam's Equity Theory. Individuals exhibit favorable behavior (collaborative) when they receive an input (equal pay) for their benefit (Organ, 1988). Employees, who perceive fairness in the organizational environment, are not willing to display behavior outside their job description and tend to perform behavior like OCB (Schnake, 1991). Hence, employees' perceived organizational justice increases their job satisfaction (Folger \& Konovsky, 1989), enhances their organizational commitment (Sweeney \& McFarlin, 1993), and increases their trust in their supervisors (Tyler $\&$ Lind, 1988). The organizational justice literature also suggests that there are interactions among the three types of justice: procedural and distributive (Brockner \& Wiesenfeld, 1996) and procedural and interactional (Skarlicki \& Folger, 1997). People use their perception of procedural and interactional justice when they evaluate or determine if the distribution of the outcome is fair (Brockner, 2002; Colquitt et al., 2001; Skitka, 2003). A lot of researches suggest that perception of organizational justice is correlated with several organizational factors, including job satisfaction (Dowden \& Tellier, 2004), organizational commitment (Kwong \& Leung, 2002), trust (Lincoln \& Kalleberg, 1990), and legitimacy (Lines, 2005).

\section{Organizational Commitment}

Organizational commitment refers to harmony and interaction between individual values and objectives of the employees and those of the organization. In other words, organizational commitment is a situation which defines the relation between employees and the organization and which helps them to decide to keep on staying with the organization (Meyer \& Allen, 1991). In other definition, organizational commitment is a psychological situation describing the relationship between employees and organization and affecting employees' desire to stay in an organization. Organizational commitment is usually defined as a psychological attachment of an individual to an organization, which can be presented by different indicators, such 
as having loyalty to the organization, internalizing the goals of the organization, and dedicating oneself to the goals of the organization (Cook \& Wall, 1980; Mowday et al., 1979). Due to its significance in management, researchers in the private sectors have examined a number of factors, both individual and organizational, related to the level of organizational commitment. Mowday et al. (1982), for example, identified four dimensions of influencing factors for organization commitment: personal characteristics (i.e., age, gender, education level), role characteristics (i.e., tenure, rank/position, role conflict, promotion opportunities), structural characteristics (i.e., organization size, span of control, existence of union, centralized authority), and work experience (i.e., group attitude, recognition, support from peers).

\section{Objectives of the Study}

The objective of the study is to investigate the relationship among trust, justice, and organizational commitment at hospitals in Nepal. The specific objective of the study is:

To determine the relationship among trust, justice, and organizational commitment in management at hospital sectors in Nepal.

\section{Hypothesis of the Study}

Based on the above literature and objective, the present study seeks the test for the following hypotheses:

Hypothesis 1. There is a relationship among organizational justice, trust in management and organizational commitment.

Hypothesis 2. There is a relationship between nurses' perceptions of trust in management and organizational commitment.

\section{Relationship among Trust, Justice and Organizational Commitment}

Organizational trust and organizational justice are important factors to promote organizational commitment. Organizational justice is not only a motivational tool but also a tool that allows the formation of trust between employees and managers in an organization (Niehoff \& Moorman, 1993). Justice in organizations is the positive attitude of employees towards their administrators when they deem that they have fairly behaved during the evaluation of the output and the way they perform their work. (Moorman, 1991). Tyler, and Lind (1992) showed that where employees have a voice and participate in the decision-making process, they are likely to have improved trust in management. In a similar view, Mayer et al. (1995) was of the view that explanation and justification for the decisions made by management culminate into perceived fairness of the interpersonal treatment received by the employees which are reciprocated by the trust. In relation, Lind (2001) adds that the use of fair procedures by management generates employees' trust because it removes feelings of exploitation among employees. The resultant trust motivates employees to reciprocate in a positive manner toward the organization (Konovsky \& Pugh, 1994). Bews and Uys (2002) emphasized management integrity in ensuring the fair and consistent application of practices, procedure, and processes in order to generate trust. Albrecht and Travaglione (2003) suggest that fairness in organizational policies and procedures is a significant determinant of trust in management. 
Based on the justice literature, it is reasonable to expect that employees will have a high level of trust in an organization if they are guaranteed fair procedural treatment (Sweeney \& McFarlin, 1993: 37). With regard to the relationship between the dimensions and the different types of commitment, Alexander and Ruderman (1987) and Aquino (1995) have reported that both distributive and procedural justices were positively related to work outcomes of employees, but that procedural justice had stronger correlations with job satisfaction, commitment, trust in upperlevel management, and evaluations by their supervisors. Alexander and Ruderman's study also found that procedural justice showed substantial unique effects on trust in management. Consequently, researchers found that trust in management was an outcome of distributive justice and trust in management was affected substantially by procedural justice (Alexander \& Ruderman, 1987: 77). Procedural justice affected the employees' organizational commitment. Procedural justice has been shown to affect the evaluation of the organization and its authorities, and thus it may exert some effects on trust in and commitment to the organization (Folger \& Konowsky, 1989: 115-130). Colquitt (2001) contends that employees who are treated fairly in terms of interpersonal justice have trust for their managers. In relation, Randolph (1995) and Whetten and Cameron (1999) in their studies found out that interactional justice in the form of sharing information raises employees to trust in management. This exchange process leads to an atmosphere of openness and confidence which in turn generates trust. In addition to it, Cropanzano and Greenberg (1997) asserted that social interaction like the nature and adequacy of information available and the extent to which employees are treated with fairness leads to trust in management and this in line with the works of Folger and Cropanzano (1998). This is further supported where employees' perception of organizational justice assists the employees to feel as members of the organization and thus develop relationships based on trust (Yilmaz \& Tasdan, 2009).

\section{Research Methodology}

Survey scales (instruments) were used to test the impact of the perceptions of nursing employees and some organizational factors upon organizational commitment. Responses to all items were made on a 5-point Likert scale ranging from (1) "Strongly Disagree" to (5) "Strongly Agree". In addition, respondents' demographic profiles such as age, gender, marital status, educational level, job position, tenure, and experience were also asked using a nominal scale. In statistical analyses, SPSS version 18.0 was used. Correlation analysis is used to show the relationship between the variables under this study. For the statistical instrument, the predictor variable of organizational justice (OJ) was measured using 20 items scale, trust in management by 21 scales, and employees' organizational commitment by 22 item scales.

\section{Nature and Sources of Data}

All the nurses have been considered as the unit of analysis for the purpose of the study. In this study, all the nurses engaged in hospital are total population. The sample was drawn from the population of total nurses registered under Nepal Nursing Council in 2014 A.D. Total numbers of nurses working in the hospital were 27,924. Multi-stage sampling was used for the selection of nurses as respondents. The sample number 
of respondents from officer and non-officer level employees includes four hundred and sixty-five in number. This study is based on a sample of 465 nurses working in Government and Non- Government Hospitals. In the study, it is investigated to find out in what extent organization commitment is related to nursing staffs' trust on their organization and the way they feel to be treated fairly when outputs are evaluated.

\section{Data Analysis}

\section{Demographic characteristics of the sample:}

Here, personal and positional factors such as age, marital status nature of hospitals, the position of the job, work experience of the respondents that influence employees' commitment were presented as follows.

Table 1

Demographic characteristics of the sample

\begin{tabular}{llcc}
\hline \multicolumn{1}{c}{ Attribute } & \multicolumn{1}{c}{ Characteristics } & $\mathrm{N}$ & $\%$ \\
\hline \multirow{3}{*}{ Age } & Below 30 & 362 & 77.8 \\
& $30-39$ & 46 & 9.9 \\
\multirow{3}{*}{ Marital Status } & 40 and above & 57 & 12.3 \\
& Not married & 247 & 53.1 \\
\multirow{2}{*}{ Duration of service (in } & Married & 218 & 46.9 \\
years) & 3 & 217 & 46.7 \\
& 3-6 & 171 & 36.8 \\
\multirow{2}{*}{ Nature of hospital } & More than 10 years & 62 & 13.3 \\
& Government & 15 & 3.2 \\
Job level & Non- government & 150 & 32.26 \\
& Managerial & 315 & 67.74 \\
& Non- managerial & 212 & 45.58 \\
& & 253 & 54.42 \\
\hline
\end{tabular}

In this study, the age range below 30 was $77.83 \%(n=362)$, between 30 to 39 age was $9.9 \%(n=46)$, and 40 and above years was $12.3 \%(n=57)$. It is interesting to note that a large portion of the nurses is younger and less number in 30 to 39 years than 40 and above years.. As for organizational tenure, 46.7\% $(n=217)$ of employees had less than 3 years working experience, 36.8\% $(n=171)$ of employees had less than 6 years working experience, $13.3 \%(n=62)$ of employees had less than 10 years working experience, and $3.2 \%(\mathrm{n}=15)$ of employees had more than 10 years working experience in their current profession. Nearly half of the nursing employees have been occupying a position for less than three years. This could be the result of a large number of new appointments made during the past three years. Two nature of hospitals are categorized involving $32.26 \%(\mathrm{n}=150)$ from government run hospitals and, $67.74 \%$ $(n=315)$ from non-government hospitals. In terms of job level, data show that 54.42 percent ( $\mathrm{n}=253$ respondents) were in non-managerial level, and 45.58 percent $(\mathrm{n}=212$ respondents) were in managerial level. 


\section{Relationship among org. justice dimensions, trust and org. commitment}

The correlation analysis was used to find the relationship among organizational justice dimensions (distributive justice, procedural justice, and interactional justice) trust in management and organizational commitment.

Table 2

Relationship among org. justice dimensions, trust and org. commitment

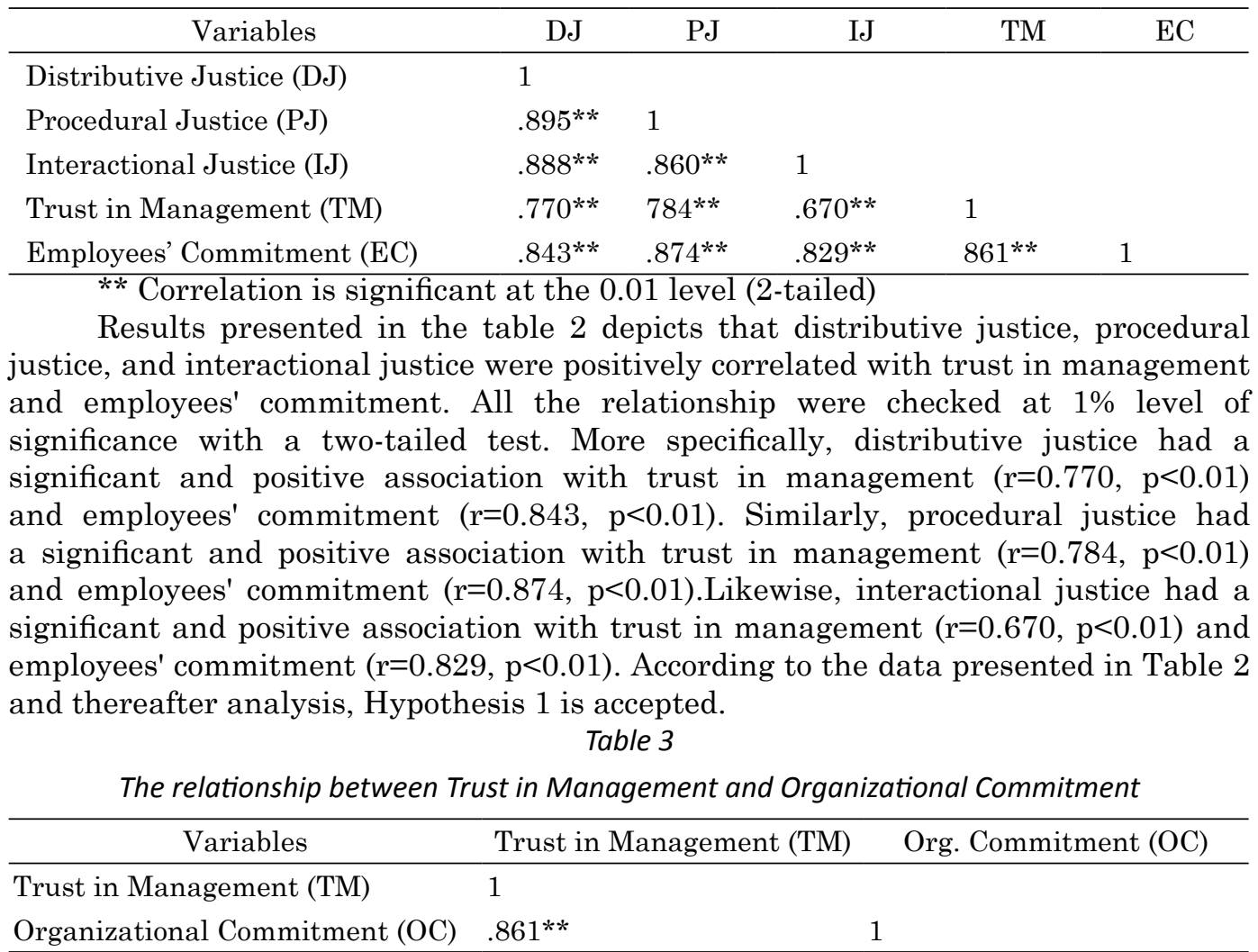

${ }^{* *}$ Correlation is significant at the 0.01 level (2-tailed).

The correlation result revealed that trust in management was positively correlated with organizational commitment. This relationship was checked at $1 \%$ level of significance with a two-tailed test. More specifically, trust in management had a significant and positive association with organizational commitment. (i.e. $r=0.861$, $\mathrm{p}<0.01)$.According to the data presented in Table 3 and thereafter analysis, Hypothesis 2 is accepted.

\section{Conclusions}

If positive feelings about trust and justice are created and continued in the organization, individuals in the organization assess this positively. This can create a structure to sustain commitment to the organization. This tendency can be supported by each individual in the organization, who has values (Mayer \& others, 1995). As for 
trust in management, employees may consider it as a result of their positive interaction with the management when they consider administrator as a representative of the organization (Konovsky\& Pugh, 1994). Alexander and Ruderman's study also found that procedural justice showed substantial unique effects on trust in management. Consequently, researchers found that trust in management was an outcome of distributive justice and trust in management was affected substantially by procedural justice (Alexander \& Ruderman, 1987). The organizational justice and trust literature suggest that trust in organization mediates the relationship between distributive justice and affective commitment as well as the relationship between procedural justice and affective commitment (Konovsky\& Pugh, 1994). Thus, it is reasonable to expect that employees will have a high level of trust, and commitment in an organization if they are guaranteed fair treatment.

\section{References}

Adams, J.S. (1965). Inequity in social exchange. In L. Berekowitz (Ed.), Advances in Experimental Social Psychology, New York: Academic Press.

Adhikari, D. R. (2009). Human Resource Management, Kathmandu: Buddha Academic Enterprises Pvt. Ltd.

Albrecht, S., \& Travaglione, A. (2003). Trust in public-sector senior management. International Journal of Human Resource Management, 24(1), 76-92.

Alexander, S., \& Ruderman, M. (1987). The Role of Procedural and Distributive Justice in Organizational Behavior. Social Justice Research, 1, 77-198.

Aquino, K. (1995). Relationships among pay equity, perceptions of procedural justice, and organizational citizenship, Employees Responsibilities and Right Journal, 18, 244-245

Bakshi, A., Kumar, K., \& Rani, E. (2009). Organizational justice perceptions as predictor of job satisfaction and organization commitment. International Journal Business Management, 4(9), 145-154.

Bews, N., \&Uys, T. (2002). The impact of organizational restructuring on perceptions of trustworthiness. South African Journal of Industrial Psychology, 28, 19-26.

Brockner, J. (2002). Making sense of procedural justice: how high procedural fairness can reduce or heighten the influence of outcome favorability. Academy of Management Review, 27, 58-76.

Brockner, J., \& Siegel, P. (1996). Understanding the interaction between procedural and distributive justice: the role of trust, in Kramer, R.M., \&Tyler, T. (Eds), Trust in Organizations, Thousand Oaks: Sage Publication.

Colquitt, JA (2001). On the dimensionality of organizational justice: a construct validation measure. Journal of Applied Psychology, 86(3), 386-400.

Cook, J., \& Wall, T. D. (1980). New work attitude measures of trust, organizational commitment, and personal need non-fulfillment. Journal of Occupational Psychology, 53, 39-52.

Cropanzano, R., \& Greenberg, J. (1997). Progress in Organizational Justice: Tunneling Through the Maze, International Review of Industrial and Organizational Psychology, 12, 317-372.

Folger, R., \& Cropanzano, R. (1998), Organizational Justice and Human Resources Management. Thousand Oaks, London: Sage Publications

Ghimire, B. (2012). Organizational Justice and Its Impact with Reference to Nepal. Germany: Lap Publishing.

Gouldner, A.W. (1960). The norm of reciprocity: A preliminary statement, American Sociological Review, 25, 161-178. 
Konovsky, M. A., \& Pugh, S. D. (1994). Citizenship behavior and social exchange. Academy of Management Journal, 37, 656-669.

Kwong, J.Y., \& Leung, K. (2002), A moderator of the interaction effect of procedural justice and outcome favourability: importance of the relationship, Organizational Behavior and Human Decision Processes, 87, 278-300.

Labour Act. (1992). Kathmandu: Government of Nepal.

Lincoln, J., \&Kalleberg, A. (1990), Culture, Control and Commitment: A Study of Work Organization and Work Attitudes in the United States and Japan, Cambridge: University Press.

Lind, E. A. (2001). Fairness heuristic theory: Justice Judgements as pivotal cognitions in organizational relations. In J. Greenberg \& R. Cropanzano (Eds.), Advances in organizational justice. Stanford, CA: Stanford University Press.

Lines, R. (2005). The structure and function of attitudes toward organizational change, Human Resource Development Review, 4, 8-32.

Mayer, R. C., Davis, J., \& Schoorman, F. (1995). An integrative model of organizational trust. Academyof Management Review, 20, 709-734.

Niehoff, Brian P., \& Moorman, Robert H. (1993). Justice as a Mediator of the Relationship between Methods of Monitoring and Organizational Citizenship Behavior. Academy of Management Journal, 36(3), 527-566.

Nursing Association of Nepal. (2000). Nursing in Nepal.The Nursing Council. 87-88.

Nursing Association of Nepal. (2002). History of nursing in Nepal. Evolution of Nursing Education. 24-49.

Organ, D.W. (1988), Organizational Citizenship Behavior: The Good Soldier Syndrome, Lexington Books: Lexington.

Ponnu, C. H., \& Chuah, C. (2010). Organizational Commitment, Organizational Justice and Employee Turnover in Malaysia. African Journal of Business Management, 4(13), 2676-2692.

Schneider, B., \& Reichers, A. E. (1983). On the etiology of climates. Personnel Psychology, 36, 19-39.

Sweeney, P. D., McFarlin, D. B., \& Cotton, J. L. (1991). Locus of control as a moderator of the relationship between perceived influence and procedural justice. Human Relations, 44, 333342. 